\title{
Contents and Distribution of Petroleum Hydrocarbons (PHC) in Jiaozhou Bay Waters
}

\author{
Dongfang Yang ${ }^{1,2,3}$, Youchi Zhang ${ }^{1}$, Jie Zou ${ }^{1}$, Qing Zhou ${ }^{1}$, Hailing Yang ${ }^{1}$ \\ ${ }^{1}$ North China Sea Environmental Monitoring Center, SOA, Qingdao, China \\ ${ }^{2}$ Shandong Provincial Key Laboratory of Marine Ecology and Environment \& Disaster Prevention and Mitigation, \\ Qingdao, China \\ ${ }^{3}$ College of Marine Science, Zhejiang Ocean University, Zhoushan, China \\ E-mail:dfyang@shou.edu.cn \\ Received July 24, 2011; revised August 18, 2011; accepted September 11, 2011
}

\begin{abstract}
Based on data from the investigation in Jiaozhou bay waters in 1979, the distribution, pollution source and seasonal variation of PHC in Jiaozhou Bay are analyzed. It is showed that in Jiaozhou bay PHC contents arrived the national Category II of the water quality standard during this year. In summer in the bay the pollution of PHC was heavy, while relatively light in spring. In the coastal waters in the east and the northeast of the bay, the PHC contents in spring surpassed the national Category II, and surpassed the national Category III. In the coastal waters, in the northeast of the bay, the change of the PHC contents formed the grads: the contents presented the falling trend from the big one to the small, which unveiled that the PHC souce in the bay mainly came from the discharge of the industrial waste water and living sewage.
\end{abstract}

Keywords: Petroleum Hydrocarbons (PHC), Distribution, Content, Source, Jiaozhou Bay

\section{Introduction}

Marine oil pollution has become the most serious and public-interested marine event, which cause serious damage to the marine and coastal environment. The production of the oil has been increasing every year. According to the estimate, in 1970 the production was 22 millions, while in the 1990 the production reached to 30 millions [1], lots of oily wastewater, oil pollution, and some other industrial effluent and the living water has been discharged into the ocean, which polluted the land as well as the coastal waters $[2,3]$. So, studying the contamination of petroleum hydrocarbons (PHC) in the coastal waters is very important to improve coastal environment and to restore the sustainable ecological development.

In this paper, based on the PHC data in 1979, we discussed the source, distribution and the transfer process of PHC, and studied the distribution characteristics and the seasonal change of the $\mathrm{PHC}$ which provided the theoretic basis for the control and restoration of the environment of the PHC pollution.

Jiaozhou Bay is a semi-closed natural inland bay, located in the central of Yellow Sea, south of Shandong Peninsula, between longitude $120^{\circ} 04^{\prime}-120^{\circ} 23^{\prime}$ and lati- tude $35^{\circ} 58^{\prime}-36^{\circ} 18^{\prime}$, its depth is shallow (average depth of $7 \mathrm{~m}$ ), the bay mouth is narrow (about $2.5 \mathrm{~km}$ ), and the time of completing the seawater exchange in the Jiaozhou bay is about 15 days [4-6]. In the eastern and northeastern coast of the Jiaozhou bay there is the Qingdao's industrial-intensive area. There are some main rivers such as Yang River and Dagu River into the Jiaozhou bay. In the east of the bay, Haibo, Licun and Lou Rivers with a lot of industrial and domestic waste water into the bay brings a lot of pollutant, causing the damage of the bay environment.

\section{Material and Method}

The data used here were recorded in May and August in 1979 by the North China Sea Environmental Monitoring Center, SOA, in eight stations: H34, H35, H36, H37, H38, H39, H40, and H41 (Figure 1). Water samples were collected according to the depth of water (if more than $15 \mathrm{~m}$, collect surface layer and bottom layer; if less than $15 \mathrm{~m}$, only collect surface layer). In the investigation and sampling, $500 \mathrm{ml}$ seawater of surface layer was collected by non-oil glass hydrophore for petroleum hydrocarbon analysis and then $1: 3 \mathrm{H}_{2} \mathrm{SO}_{4}$ solution was added in the sample immediately, and adjusted the sam 


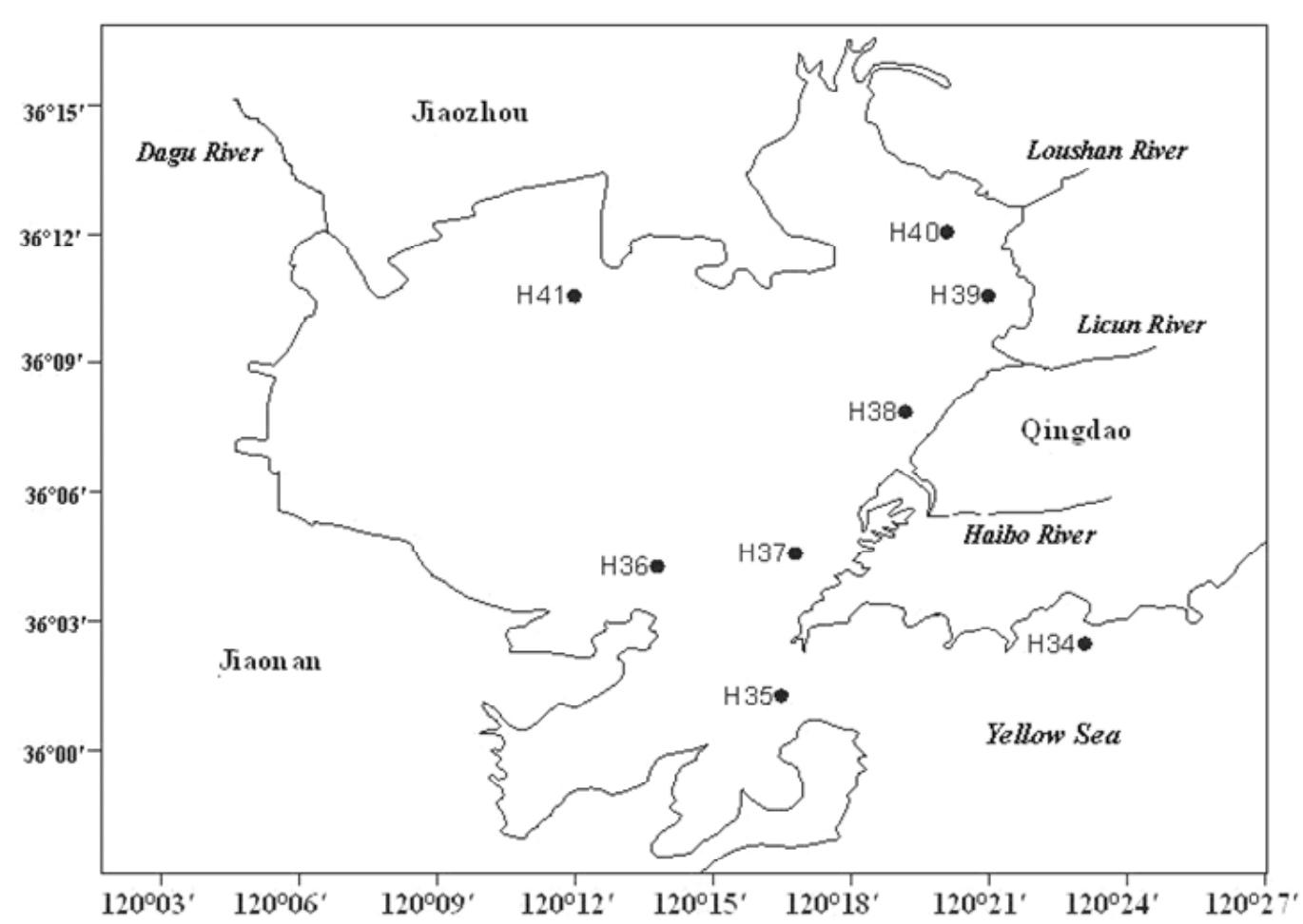

Figure 1. Investigation sites in Jiaozhou Bay.

ple to weak acid $(\mathrm{Ph} \approx 4)$, and then extracted it twice with $0.01 \mathrm{~m}^{3}$ petroleum ether and stored it at $(5 \pm 2)^{\circ} \mathrm{C}$ away from light. In the lab 751 GD ultraviolet spectrophoto- meter was used to mensurate oil content in water sample, which was used with the same the method as in Monitoring Standards of Ocean (GB 17378. 3, 4, 7 - 1998).

\section{Results}

\subsection{Amount of Content}

In May, in the surface water in the whole Jiaozhou Bay, the PHC content ranged from 0.08 to $0.32 \mathrm{mg} / \mathrm{L}$, whose seawater quality was worse than Category I $(0.05 \mathrm{mg} / \mathrm{L})$ of the National Standard of China for Seawater Quality GB3097-1997(in which 3 categories 1 to 3 are classified from the best to the worst). Except for station H38, the seawater quality in the whole waters reached the Category II $(0.30 \mathrm{mg} / \mathrm{L})$. The seawater quality only in the waters of station $\mathrm{H} 38$ was worse than the Category II $(0.30 \mathrm{mg} / \mathrm{L})$.

In August, the PHC content in the water body increased distinctly, reaching 0.10 to $1.10 \mathrm{mg} / \mathrm{L}$, whose seawater quality in the whole waters was worse than the Category I $(0.05 \mathrm{mg} / \mathrm{L})$. Except for station H39, the seawater quality in the whole waters reached the Category II $(0.30 \mathrm{mg} / \mathrm{L})$. Only the seawater quality of station H39 was worse than the Category III $(0.50 \mathrm{mg} / \mathrm{L})$ (Table 1).

\subsection{Horizontal Distribution}

In May, in the surface water in the Jiaozhou Bay, the PHC content decreased from the northeast to the southwest gradually, declining from $0.32 \mathrm{mg} / \mathrm{L}$ to $0.08 \mathrm{mg} / \mathrm{L}$. In the surface water off the shore between estuaries of Haibo River and Licun River which were the adjacent rivers in the east, there was a series of semi-concentric circles with the center of $\mathrm{H} 38$ where PHC was the highest $(0.32 \mathrm{mg} / \mathrm{L})$, and decreased generally outwards, evidently higher than that in the southwestern waters including the center, mouth and outside of the bay (Figure 2).

In summer, the isoline (Figure 3 ) on the PHC content in the surface water showed that with station H39 as the center, a series of semi-concentric circles in different gradients formed. In the northeast of the Bay there was the two adjacent rivers of Licun River and Loushan River, and in the coastal waters between the estuaries of these two rivers, there was an area with a high content of

Table 1. the surface water quality in Jiaozhou Bay in May and August.

\begin{tabular}{lll}
\hline & May & August \\
\hline $\begin{array}{l}\text { PHC content in } \\
\text { seawater }(\mathrm{mg} / \mathrm{L})\end{array}$ & $0.08-0.32$ & $0.10-1.10$ \\
$\begin{array}{l}\text { The National Standard } \\
\text { of China for Seawater } \\
\text { Quality }\end{array}$ & Category II and III & Category II andIII \\
\hline
\end{tabular}




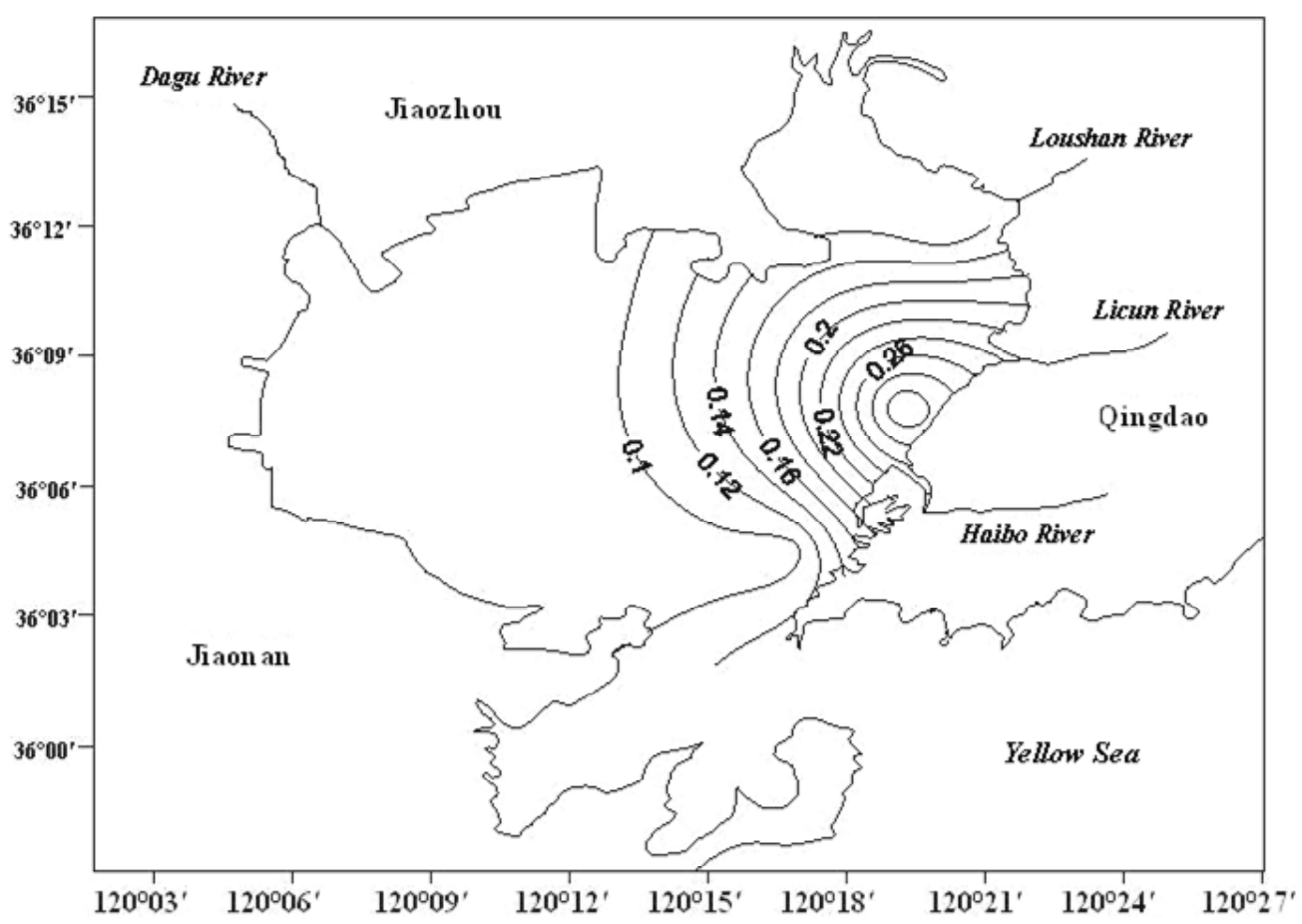

Figure 2. PHC distribution at the surface in Jiaozhou Bay in May (mg/L).

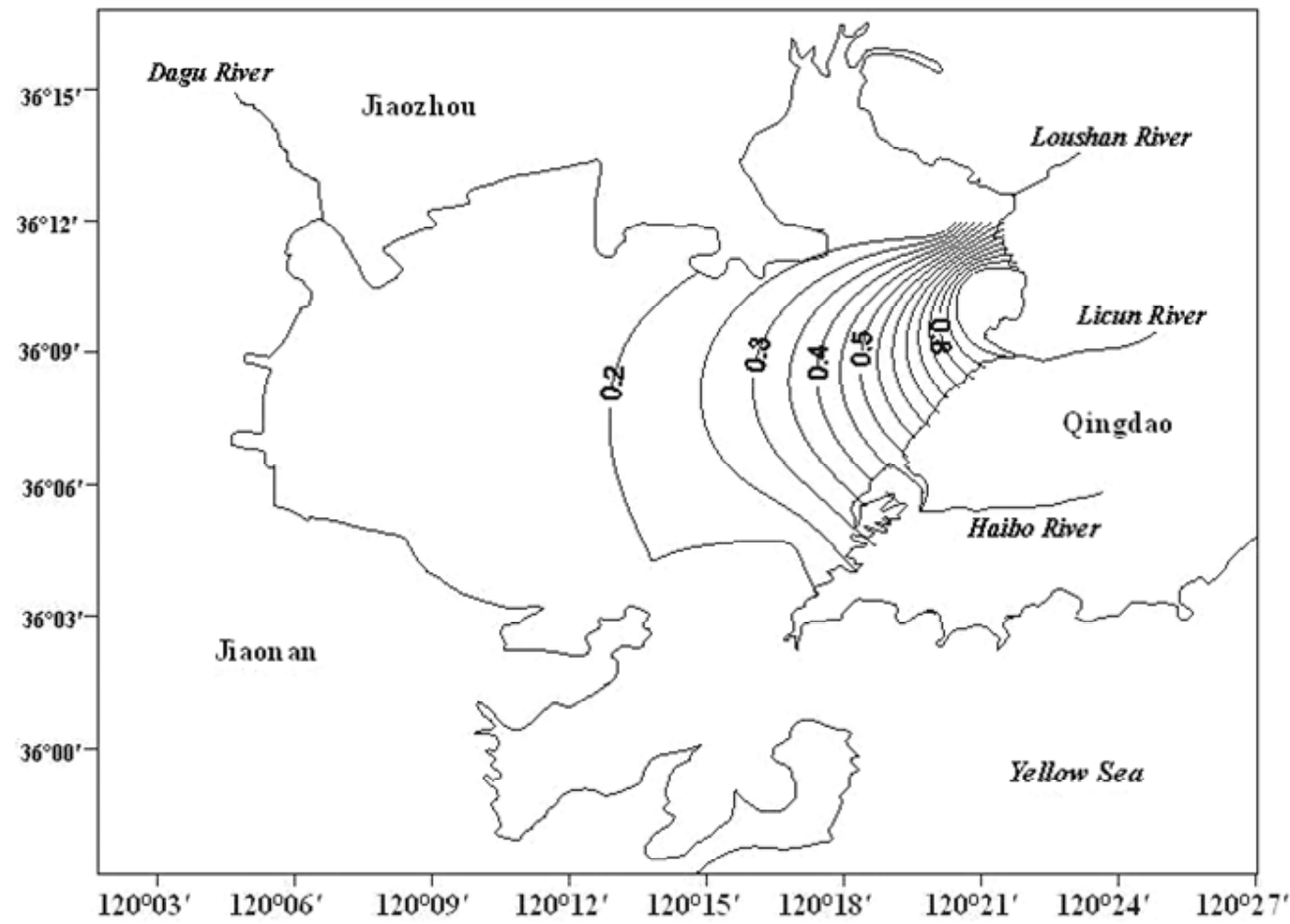

Figure 3. PHC distribution at the surface in Jiaozhou Bay in August (mg/L).

PHC. With station H39 as the center, the PHC content declined from a high content $(1.10 \mathrm{mg} / \mathrm{L})$ in the center to along the gradients. From the coastal waters in the north- east to the central waters of the Bay, the PHC content $\mathrm{d}$ creased from $1.10 \mathrm{mg} / \mathrm{L}$ to $0.10 \mathrm{mg} / \mathrm{L}$. In this way, along the flowing direction of the Haibo River, Licun 
River and Loushan River, the PHC content in the water body in Jiaozhou Bay fell gradually (Figure 3).

\subsection{Seasonal Distribution}

In spring, in the whole water body of Jiaozhou Bay, the PHC content range in the surface water was from 0.08 $\mathrm{mg} / \mathrm{L}$ to $0.32 \mathrm{mg} / \mathrm{L}$, while in summer it was from 0.10 $\mathrm{mg} / \mathrm{L}$ to $1.10 \mathrm{mg} / \mathrm{L}$, reaching a very high value. At stations $\mathrm{H} 34$ and H40, the minus value between the PHC contents in August and May were minus, ranging from -0.02 to -0.01 , but the values of other stations were positive, ranging from 0.01 to 0.91 . Station H34 was located outside of the Bay, while station H40 was in the northernmost part of the Bay, which demonstrated that in the surface water body of the Jiaozhou bay, almost all the PHC content in the surface in summer surpassed that in spring.

\section{Discussion}

\subsection{Water Quality}

In the Jiaozhou Bay waters, the PHC content in spring reached the Category II and III, so did it in summer. In addition, in summer, the PHC content in some waters was far beyond the Category III, which indicated that PHC had seriously polluted the waters. Therefore, in the whole year, the waters of the Jiaozhou Bay were seriously polluted by PHC in spring, while the pollution was even more severe in summer.

\subsection{Pollution Sources}

In the temporal scale, the PHC change in between spring and summer was taken into consideration. The results showed that in Jiaozhou bay, almost all the PHC content in the surface water in summer was higher than that in spring. Thus, from spring to summer, the PHC content in the whole waters of the bay increased. In addition, in spatial scale, the estuaries of Haibo River, Licun River and Loushan River were in the northeastern waters of Jiaozhou Bay, and these rivers provided a transport for the northeastern coastal waters of the bay. Along the flowing direction of rivers, the change of PHC content with gradients showed a declining tendency from the high content to low. In spring, in the coastal waters between the estuaries of these two rivers, Haibo River and Licun River, an area with a high PHC content formed; in summer, in the coastal waters between the estuaries of the two rivers, Licun River and Loushan River, an area with a high PHC content also formed. The results indicated that Haibo River, Licun River and Loushan River in the northeast in Jiaozhou Bay were the main sources of PHC pollution.

\subsection{Transfer Process}

In the waters of Jiaozhou bay, the PHC content transfered from the estuary to the outside of the bay.

In the eastern and northeastern coast of the Jiaozhou bay, there were industry-intensive areas in Qingdao city. Thus, the industrial wastewater and the domestic sewage were discharged a lot. There existed three rivers, including Haibo River, Licun River and Loushan River along the eastern and northeastern coast of the Jiaozhou Bay, which played the function of discharging the industrial wastewater and the domestic sewage into the Jiaozhou Bay, bringing a large number of pollutants with PHC into the bay.

In spring, Haibo River and Licun River run into the sea in the northeast of the bay, bringing a large amount of PHC from the land, and leading to serious pollution of PHC in the eastern and northeastern areas of Jiaozhou bay. The results revealed that the PHC content was higher in the northeastern areas of the Bay, decreasing gradually towards the southwest. And the PHC content in spring was comparatively lower in the waters of Jiaozhou bay.

In summer, Licun River and Loushan River ran into the sea from the northeast of the Bay, bringing a large amount of PHC from the land. At the same time, the rivers in the rainy season resulted in a widespread increase of PHC content in the whole waters body of Jiaozhou bay. The results revealed that in summer, the PHC content began to increase gradually in the eastern and northeastern areas of Jiaozhou Bay, and it was higher, decreasing gradually towards the southwest. And the PHC content in summer was comparatively higher in the waters of Jiaozhou bay. The content of PHC was high in the waters of the Jiaozhou Bay.

\section{Conclusions}

In May, the PHC content in the whole waters of Jiaozhou bay reached the Category II, and in the coastal waters of the bay northeast, it reached the Category III. In addition, in other waters including the center, mouth and outside of the bay, it reached the Category II .

In August, the PHC content in the whole waters of Jiaozhou bay reached the Category II and III, and in the coastal waters of the bay northeast, it was worse than the Category III. On the other hand, in other waters including the center, mouth and outside of the bay, it reached the Category II. The results showed that in the temporal scale it has been increasing from spring to; in the spacial 
scale, from the coastal waters of the bay northeast to other bay waters such as the center, mouth and outside of the bay, it decreased.

The Haibo River, Licun River and Loushan River, their estuaries in the waters of the bay northeast, brought a lot of industrial wastewater and domestic sewage, leading to the higher PHC content in waters of the bay northeast than that in other bay waters. As the rainfall in summer obviously increased, the PHC content in the waters of the bay northeast would become even higher.

Therefore, the PHC in Jiaozhou bay mainly came from industrial wastewater and domestic sewage, which showed that the protection of the environment was strengthened, resulting in the fact that the PHC pollution would be reduced.

\section{References}

[1] S. C. Wilson and K. C. Jones, "Bioremediation of Soil Contaminated with Polynuclear Aromatic Hydrocarbons (PAHs): A Review," Environmental Pollution, Vol. 81, No. 3, 1993, pp. 229-249. http://dx.doi.org/10.1016/0269-7491(93)90206-4

[2] Y. Sun, Y. Cui and H. Yu, "The Analysis of the Distribution and Pollution of the PHC, COD and $\mathrm{Cr}$," Marine
Aquatic Study, Vol. 13, No. 13, 1992, pp. 123-129.

[3] J. M. Pan, C. X. Qi and X. Y. Liu, "The Relation of the PHC Distribution and the Estuary Environment in the Sediment in the Zhujiang Estuary," Marine Environmental Science, Vol. 21, No. 2, 2002, pp. 23-27.

[4] D. F. Yang, J. Zhang, J. B. Lu, Z. H. Gao and Y. Chen, "Examination of Silicate Limitation of Primary Production in the Jiaozhou Bay, North China I .Silicate Being a Limiting Factor of Phytoplankton Primary Production," Chinese Journal of Oceanology and Limnology, Vol. 20, No. 3, 2002, pp. 208-225.

[5] D. F. Yang, J. Zhang, Z. H. Gao, Y. Chen and P. Y. Sun, "Examination of Silicate Limitation of Primary Production in the Jiaozhou Bay, North China II. Critical Value and Time of Silicate Limitation and Satisfaction of the Phytoplankton Growth," Chinese Journal of Oceanology and Limnology, Vol. 21, No. 1, 2003, pp. 46-63.

[6] D. F. Yang, Z. H. Gao, Y. Chen, J. Zhang and P. G. Wang, "Examination of Silicate Limitation of Primary Production in the Jiaozhou Bay, North China III. Judgment Method, Rules and Uniqueness of Nutrient Limitation among N, P, and Si," Chinese Journal of Oceanology and Limnology, Vol. 21, No. 2, 2003, pp. 114-133. 